\title{
TWO NEW SPECIES OF COPEPODS PARASITIC ON JAPANESE FISHES
}

$\operatorname{AUTHOR}(\mathrm{S})$ :

Yamaguti, Satyu; Yamasu, Terufumi

\section{CITATION:}

Yamaguti, Satyu ...[et al]. TWO NEW SPECIES OF COPEPODS PARASITIC ON JAPANESE FISHES. PUBLICATIONS OF THE SETO MARINE BIOLOGICAL LABORATORY 1960, 8(1): 137140

ISSUE DATE:

1960-05-30

URL:

http://hdl.handle.net/2433/174696

RIGHT: 


\title{
TWO NEW SPECIES OF COPEPODS PARASITIC ON JAPANESE FISHES ${ }^{13}$
}

\author{
SATYU YAMAGUTI \\ Zoological Institute, Kyoto University \\ and \\ TERUFUMI YAMASU \\ Tamano Marine Laboratory, Okayama University
}

With Plate IX

Of the two species described here, one was found at the Tamano Marine Laboratory of Okayama University, and the other at the Fish Culture Ground of Kinki University at Sirahama, Wakayama Prefecture. Thanks are due to the authorities of the two institutions for their generous supply of the material.

\section{Family CHONDRACANTHIDAE}

1. Pseudacanthopsis secunda n. sp.

(Pl. IX, Figs. 1-6)

Habitat: Gills of Apogon lineatus Temm. et Schleg.

Material: 5 gravid females.

Locality and date: Inland Sea, August, 1959.

Body $1.3-1.5 \mathrm{~mm}$ in length, including first antenna and posterior lobe of trunk. Cephalothorax semicircular $0.5-0.55 \times 0.650 .73 \mathrm{~mm}$, with its anterolateral corner produced prominently in form of a rounded prominence and its convex frontal margin bordered by T-shaped, heavily sclerotized rib. Neck short. Trunk 0.85$1.0 \times 0.9-1.2 \mathrm{~mm}$, strongly convex dorsally and broadly rounded anteriorly and laterally, with paired, rounded, conical, posterior lobes projecting backward beyond abdomen. Genital segment small, inverted trapezoidal, about $60 \mu \mathrm{long}, 0.14 \mathrm{~mm}$ broad at base. Abdomen wider than long, about $0.05 \times 0.1 \mathrm{~mm}$, with broadly rounded

1) Contributions from the Tamano Marine Laboratory, Okayama University, No. 67.

Publ. Seto Mar. Biol. Lab., VIII (1), 1960. (Article 11) 
posterior corners, on the dorsal side of which the caudal rami are attached. Caudal rami unsegmented, about $50 \mu$ long $20 \mu$ broad at its swollen proximal portion which is constricted off from the abdomen; distal portion tapering to a sharp point. Egg sac cylindrical, about $2.0 \times 0.3 \mathrm{~mm}$; eggs rounded, in several longitudinal rows.

First antennae rod-shaped, sigmoid, unsegmented, arising immediately anteroventral to frontal margin as paired spherical protuberances and crossing anterolateral corners of head ventrally; they may or may not project outward and backward beyond the lateral margins of the head, each with three very fine setae at its blunt tip. Second antennae strong prehensile claws set on sclerotized, elevated base, with their incurved sharp points crossing each other. Mandible nodular at base, with apparently bilaterally pectinate, curved blade. First maxilla with two short blunt-pointed spines. Second maxilla with curved terminal claw. Maxilliped right-angled near base, terminating in a short prehensile claw.

First leg lateral to mouth parts, terminating in a large spherical knob; second leg immediately posteromedial to first, divided into three rami ; inner ramus plump, tipped with three rudimentary spines close together; outer ramus rounded, unarmed, giving rise on its medioposterior margin to a circular lobe a little smaller than itself.

This species differs from $P$. apogonis YAMAGUTI et YAMASU, 1959, the only known member of the genus, in the trunk lacking anterior lobes and in the shape and structure of the first antennae, mandible, caudal rami and legs.

\section{Family LERNAEOPODIDAE}

2. Brachiella seriolae $\mathrm{n}$. sp.

(P1. IX, Figs. 7-14)

Habitat: Pectoral fin of Seriola quinqueradiata Temm. et Schleg.

Material: Three mature females without egg strings.

Locality and date: Fish Culture Ground of Kinki University at Sirahama, Wakayama Prefecture; October 31, 1959.

Body straight, about $8-9 \mathrm{~mm}$ in length excluding posterior processes, with maximum width of $1.7-2.0 \mathrm{~mm}$ near squarely truncted posterior end of trunk. Carapace longer than wide, $1.2-1.4 \times 0.95-1.1 \mathrm{~mm}$, with median rib dorsally. Neck practically lacking. Trunk $6.6-6.8 \times 1.7-2.0 \mathrm{~mm}$, enlarged in greater posterior portion containing paired ovaries and uteri, especially across posterior margin. It is interesting to note that the uterus containing a series of about 40 flattened eggs is seen close to the posterior lateral margin as a clear vermiform organ with its recurved posterior end leading to the wide dorsal uterine pore at the posterolateral corner of the genital segment. In view of absence of the external 
egg strings these uteri apparently functional as egg strings; in one specimen both uteri have discharged the contents and their walls are crumbled all together. There are two pairs of cylindrical posterior processes, of which the dorsal originating close to each posterolateral corner of the trunk is $1.3-1.7 \mathrm{~mm}$ long by $0.28-$ $0.36 \mathrm{~mm}$ wide, while the ventral originating from the ventral surface of the genital segment close to the median line is $4.1-4.6 \mathrm{~mm}$ long by $0.3-0.4 \mathrm{~mm}$ wide. Genital segment or process short, $0.4-0.5 \times 0.8-0.9 \mathrm{~mm}$, with a distinct notch on each side of its median, terminal, anal cone.

First antenna 5-segmented ; conical terminal segment with one minute delicate spine on inner margin, tipped with 7 minute spiniform processes, one of which is larger than the others. Second antennae biramose, bent down across mouth aperture endopod appressed against exopod, with file-like surface ventrally; exopod indistinctly two-segmented, with a claw-like spine and a seta at tip. Mouth tube with a complete circle of very fine leaflets. Mandible with 11 teeth, of which the second, fourth and sixth are distinctly smaller than the first, third and fifth respectively. Maxilla bipartite, with one minute and two longer setae at tip; palp with two minute terminal setae. First maxillipeds about $2.7 \mathrm{~mm}$ long, separate to tips, where they are expanded; bulla goblet-shaped, strongly sclerotized at base; when pressed against the trunk they reach to the level of the anterior ends of the ovary. Second maxilliped held at right angles to the body axis, consisting of a stout basal segment and a slender terminal segment nearly half as long; basal segment with a seta on medioventral margin just at the notch where the terminal claw shuts down; terminal segment with a pectinate rod terminating in a minute spine on its concave distal margin, and the terminal claw is provided with a slender accessory claw. These maxillipeds are attached so far forward that they almost reach the maxillary palps.

This species resembles Brachiella elegans RICHIARDI, 1880, so closely that we were able to find differences in the characters of the second antenna and the length of the first maxilliped (second maxilla of WILSON) alone. According to WILSON who first published a full description of B. elegans, the exopod (endopod of WILSON) of the second antenna is bilobed at the tip and armed with tiny spines, and the first maxillipeds are $1.75 \mathrm{~mm}$ long, whereas in the present species the exopod of the second antenna is not bilobed and the first maxilliped is $2.7 \mathrm{~mm}$ long.

\section{LITERATURE CITED}

WILson, C. B. 1915. North American parasitic copepods belonging to the Lernaeopodidae, with a revision of the entire family. Proc. U.S. Nat. Mus. 47, 565-729.

Yamaguti, S. and Yamasu, T. 1959. Parasitic copepods from fishes of Japan, with descriptions of 26 new species and remarks on two known species. Biol. J. Okayama University 5 (3-4), 89-165. 


\section{EXPLANATION OF PLATE IX}

Figs. 1-6. Pseudacanthopsis secunda n. sp., female.

1. Female, dorsal view. 2. Genital segment, abdomen and caudal rami. 3. First antenna. 4. Second antenna. 5. Mandible, first and second maxillae and maxilliped. 6. First and second legs.

Figs. 7-14. Brachiella seriolae n. sp., female.

7. Female, dorsal view. 8. First antenna. 9. Second antenna. 10. Mandible. 11. Maxilla. 12. First maxillipeds. 13. Second maxilliped. 14. Terminal portion of second maxilliped. 
Publ. Seto Mar. Biol. Lab., VIII, 1 (1960)

PLATE IX
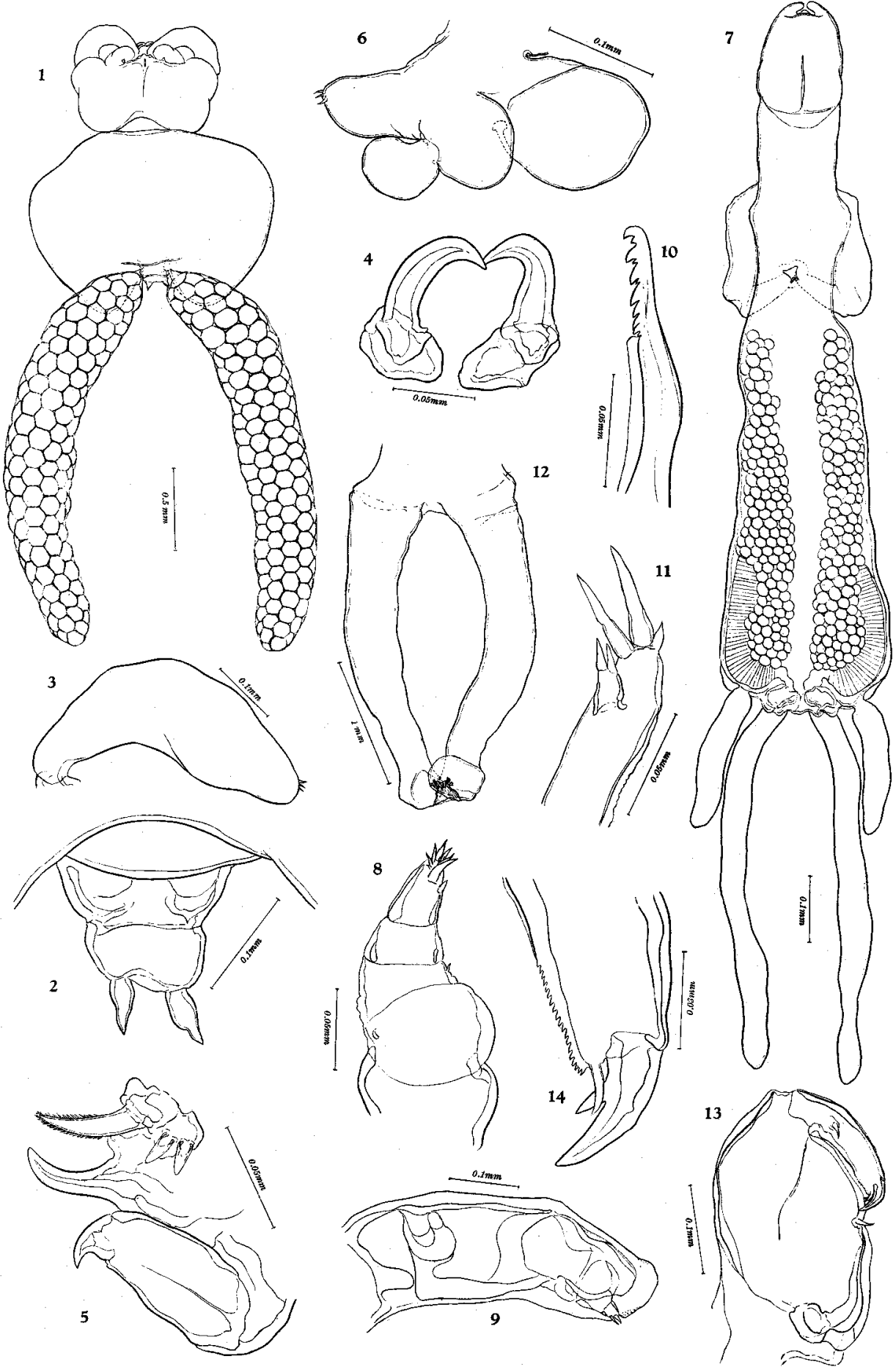

S. Yamaguti and T. Yamasu: Two New Species of Copepods Parasitic on JAPANESE Fishes. 